\title{
Prognosis of advanced stage non-small-cell lung cancer patients receiving chemotherapy: adenocarcinoma versus squamous cell carcinoma
}

Noorwati Soetandyo, ${ }^{1}$ Arif Riswahyudi Hanafi, ${ }^{2}$ Sri Agustini, ${ }^{1}$ Dian Triana Sinulingga ${ }^{3}$

pISSN: 0853-1773 • elSSN: 2252-8083 https://doi.org/10.13181/mji.oa.203787 Med J Indones. 2020;29:26-31

Received: May 26, 2019

Accepted: February 19, 2020

Authors' affiliations:

'Department of Hematology and Medical Oncology, Dharmais National Cancer Center Hospital, Jakarta, Indonesia, ${ }^{2}$ Department of Pulmonology, Dharmais National Cancer Center Hospital, Jakarta, Indonesia, ${ }^{3}$ Dharmais National Cancer Center Hospital, Jakarta, Indonesia

\section{Corresponding author:}

Noorwati Soetandyo

Department of Hematology and Medical Oncology, Dharmais National Cancer Center Hospital, Jalan Letjen S. Parman No. 84-86, Palmerah, West Jakarta 11420, DKI Jakarta, Indonesia Tel/Fax: +62-21-5681570 ext. 2356/ $+62-21-56969561$

E-mail: noorwatis3@yahoo.com; noorwatisoetandyo@gmail.com

\begin{abstract}
BACKGROUND In Indonesia, lung cancer is one of the most prevalent solid cancer with the highest mortality rate. However, studies to identify prognostic factors associated with mortality are lacking. Thus, this study was aimed to determine the association of histological subtypes and prognosis of advanced stage non-small-cell lung cancer (NSCLC) patients receiving chemotherapy.
\end{abstract}

METHODS This study focused on a retrospective cohort consisting of 60 patients with advanced stage NSCLC and treated with chemotherapy. Patients with NSCLC stage IIIB or stage IV, age $\geq 18$ years, and good performance status were recruited. The outcomes were one-year mortality and treatment response. Gender, age, body mass index, staging, and performance status were evaluated. Chi-square and Fisher's exact tests were used.

RESULTS Two common histological subtypes, adenocarcinoma (68.3\%) and squamous cell carcinoma (31.7\%), were observed among all subjects. Four patients (6.7\%) died during one-year observation period. Mortality rate was higher in squamous cell carcinoma (10.5\%) patients than in adenocarcinoma (4.9\%). Underweight patients had higher risk of death (relative risk $[\mathrm{RR}]=1.09,95 \%$ confidence interval $[\mathrm{Cl}]=1.00-1.19$ ) and disease progression $(R R=1.30,95 \% \mathrm{Cl}=1.12-1.51)$. In adenocarcinoma, metastasis was a risk for progressive disease $(R R=1.35,95 \% \mathrm{Cl}=1.09-1.66)$. In squamous cell carcinoma, men had a lower risk of disease progression $(R R=0.11,95 \% \mathrm{Cl}=0.03-0.41)$.

CONCLUSIONS Squamous cell carcinoma had comparable one-year mortality and disease progression rate with adenocarcinoma type in advanced stage NSCLC. However, underweight patients had a higher risk of mortality and disease progression.

KEYWORDS chemotherapy, histology, lung cancer, prognosis
Lung cancer, particularly non-small-cell lung cancer (NSCLC), is considered one of the major causes of death in many countries, particularly developing ones..$^{1-3}$ The reason is that the disease is often asymptomatic in the early stages. ${ }^{4,5}$ Thus, most of the lung cancer cases can only be diagnosed in advanced stages, thereby resulting in high mortality rates. ${ }^{4}$

Chemotherapy remains the primary treatment for advanced stage NSCLC, notably among good performance patients with negative or unknown results of targetable driver mutations. ${ }^{4,6}$ Many studies have shown the efficacy and effectiveness of chemotherapy in those patient populations. ${ }^{3,4,7,8}$ However, most patients still had poor prognosis.

Numerous studies have compared the prognosis between NSCLC and small-cell lung cancer. However, research on the prognosis of each histological subtype in NSCLC, especially in advanced stages, is limited. 
Although histological subtype was known as one of the important prognostic factors in advanced stage NSCLC, ${ }^{9,10}$ results were conflicting. Some studies found that adenocarcinoma patients had better prognosis.,11 Another study suggested that no difference existed in the prognosis according to histological subtypes. ${ }^{12}$ In addition, gender, staging, and body mass index (BMI) were also identified as valuable prognostic factors of mortality. $\cdot{ }^{9,13,14}$

Histological subtype in patients with advanced stage NSCLC receiving chemotherapy is crucial to develop a personalized treatment. Through this approach, the sub-optimal result of "one size fits all" approach in chemotherapy could be modified to improve survival and minimize harm. ${ }^{15}$ This study was aimed to determine the association between histological subtypes and prognosis of advanced stage NSCLC patients receiving chemotherapy in Indonesia. The role of gender, age, BMI, staging, and performance status were also evaluated in determining the prognosis.

\section{METHODS}

This retrospective cohort study was conducted at the National Cancer Center, where medical records and electronic health records were collected and analyzed. This study has been approved by the Ethical Committee of Dharmais National Cancer Center (No: 050/KEPK/ IV/2018). Inclusion criteria were as follows: newly diagnosed patients with histologically proven stage IIIB or stage IV NSCLC from January 2013 to December $2016, \geq 18$ years, received chemotherapy for NSCLC, and had Eastern Cooperative Oncology Group Performance Status (ECOG-PS) scale in the range of 0-2. Patients with incomplete medical record, or who had received any targeted therapy or immunotherapy, were excluded. The follow-up was performed for a year.

Histological subtypes of lung cancer were determined by assessing the lung tissue obtained through transthoracic biopsy procedure. Staging of NSCLC was defined according to the definition by the American Joint Committee on Cancer. ${ }^{16}$ Furthermore, tumor histology was classified as reported by 2015 World Health Organization classification of lung tumors. ${ }^{17}$

During the first visit, age, sex, BMI, history of smoking, comorbidity, staging, and ECOG-PS were recorded. Clinical examination, laboratory tests, abdominal ultrasonography, and computed tomography scan were also taken on the first visit, after three cycles of chemotherapy and at the end of six cycles of chemotherapy to determine treatment response. Treatment response was assessed based on the response evaluation criteria in solid tumor guidelines. ${ }^{18}$ One-year mortality was evaluated after the first chemotherapy session.

The comparison of two proportions formula was used to determine the sample size and obtained a minimum sample size of 98 . To optimize the power of the research, total sampling was used in recruiting study subjects. Student's t-test was conducted to compare age and BMI by histological type (adenocarcinoma and squamous cell carcinoma). Chi-square or Fisher's exact test was conducted to compare sex, history of smoking, comorbidity, staging, and ECOG-PS by histological type.

Time-to-event data were not available. Chi-square tests or Fisher's exact tests were conducted to identify the prognostic factors associated with oneyear mortality and treatment response. Relative risks (RRs) and their 95\% confidence intervals (Cls) were also calculated. All $p$-values were two-sided. Statistically significant differences were considered if the $p$-values were $<0.05$. The entire analysis was performed on SPSS, version 24.0 (IBM Corp, USA).

\section{RESULTS}

A total of 98 newly diagnosed NSCLC patients were eligible for this study. Thirty patients were excluded because they had received targeted therapy and eight were excluded because of incomplete medical records. Among the subjects, 60 completed the oneyear follow-up period. This study showed that the most common histological subtype of advanced stage NSCLC was adenocarcinoma. Table 1 showed the patients' characteristics. Compared with squamous cell carcinoma patients, adenocarcinoma patients were younger and had better ECOG performance status. However, a slightly higher proportion of metastasis in adenocarcinoma patients (75.6\%) was observed compared with squamous cell carcinoma patients (52.6\%). Regarding the type of chemotherapy, approximately $95 \%$ of the patients received platinumbased chemotherapy.

During the one-year observation period, four patients $(6.7 \%)$ died. Mortality rate in squamous cell carcinoma patients was not significantly higher than 
that in adenocarcinoma patients (10.50\% versus $4.90 \%$, $p=0.58)$. Among all patients, underweight ones had a slightly higher risk of death $(R R=1.09,95 \% \mathrm{Cl}=1.00-$ 1.19). In each histological subtype, age, gender, BMI, presence of comorbidity, history of smoking, and ECOG performance status were not a significant prognostic factor to increase the one-year mortality rate (Table 2).

In terms of treatment response, no patient had a complete response to treatment. Progressive disease was observed in $19.5 \%$ of adenocarcinoma patients and $15.8 \%$ of squamous cell carcinoma patients ( $p=$ 1.00). Among all the patients, being underweight was determined as a prognostic factor of progressive disease $(\mathrm{RR}=1.30,95 \% \mathrm{Cl}=1.12-1.51)$. In the adenocarcinoma group, subjects with metastasis $(R R=1.35,95 \%$ $\mathrm{Cl}=1.09-1.66)$ or were underweight $(\mathrm{RR}=1.32,95 \% \mathrm{Cl}=$ 1.09-1.60) had a higher risk of having progressive disease. Among the squamous cell carcinoma patients, women had a higher risk of progressive disease than men.

\section{DISCUSSION}

In Indonesia, more than $90 \%$ of lung cancer cases were diagnosed in the advanced stage. ${ }^{19}$ Five-year survival rate of lung cancer in developing countries was only $8.9 \%$ and lower in advanced stage disease. ${ }^{20}$ In our study population, adenocarcinoma was the leading histological subtype of NSCLC. This result is comparable with the previous descriptive study by Harsal et al, ${ }^{19}$ which found that adenocarcinoma was more frequent (54\%) than squamous cell carcinoma (22\%). Adenocarcinoma patients were significantly younger and had better ECOG performance status than squamous cell carcinoma patients. The same findings were reported in a study by Thomas et al, ${ }^{21}$ showing that younger patients had a higher risk of adenocarcinoma ( $59 \%$ versus $42 \%$ ) than squamous lung cancers (10\% versus $24 \%$ ) compared with the older population. This result was supported by another study in Japan.22 Pathogenesis underlying these findings remains unknown. However, as adenocarcinoma is mostly found in non-smoker patients, genetic factors could be one of the reasons why adenocarcinoma was more frequently observed in younger patients. Further studies are needed to confirm this hypothesis.

To our knowledge, this is the first study on the Southeast Asian population to evaluate the role of histological subtypes in the prognosis of patients with advanced stage NSCLC receiving chemotherapy. This study considered only two dominant histological subtypes; adenocarcinoma and squamous cell carcinoma. Contradictory findings between one-year mortality and progressive disease were presented in this study. Adenocarcinoma subtypes had a higher proportion of one-year mortality rate compared with squamous cell carcinoma (4.90\% versus $10.50 \%$ ) but higher progression of disease (19.50\% versus $15.80 \%$ ). Several reasons could be considered to explain this finding. First is due to the baseline characteristics of each group. As found in other studies, most patients with squamous cell subtypes are older ( $57.9 \%$ of patients were elderly), and $89.5 \%$ of patients were in ECOG $1-2.23-25$ At the same time, a higher proportion of stage IV adenocarcinoma patients was related to natural

Table 1. Characteristics of patients

\begin{tabular}{|c|c|c|c|c|}
\hline Characteristics & Adenocarcinoma, $n(\%)(n=41)$ & SCC, $n(\%)(n=19)$ & Total & $p$ \\
\hline \multicolumn{5}{|l|}{ Age (years), mean (SD) } \\
\hline Age group (years) & $53.1(10.0)$ & $59.0(10.3)$ & $55.0(10.4)$ & 0.04 \\
\hline$\geq 60$ & $10(24.4)$ & $11(57.9)$ & $21(35.0)$ & 0.01 \\
\hline$<60$ & $31(75.6)$ & $8(42.1)$ & $39(65.0)$ & \\
\hline BMI group $\left(\mathrm{kg} / \mathrm{m}^{2}\right)$, mean (SD) & $22.4(3.4)$ & $23.0(4.1)$ & $22.6(3.6)$ & 0.57 \\
\hline$\geq 18.5$ & $33(80.5)$ & $15(78.9)$ & $48(80.0)$ & 0.89 \\
\hline$<18.5$ & $8(19.5)$ & $4(21.1)$ & $12(20.0)$ & \\
\hline \multicolumn{5}{|l|}{ ECOG } \\
\hline $1-2$ & $24(58.5)$ & $17(89.5)$ & $41(68.3)$ & 0.02 \\
\hline 0 & $17(41.5)$ & $2(10.5)$ & $19(31.7)$ & \\
\hline Male sex & $32(78.0)$ & $18(94.7)$ & $50(83.3)$ & 0.11 \\
\hline Metastasis & $31(75.6)$ & $10(52.6)$ & $41(68.3)$ & 0.07 \\
\hline Comorbidity & $18(43.9)$ & $9(47.4)$ & $27(45.0)$ & 0.8 \\
\hline Smoking history & $27(65.9)$ & 15 (78.9) & $42(70.0)$ & 0.3 \\
\hline
\end{tabular}

mji.ui.ac.id 


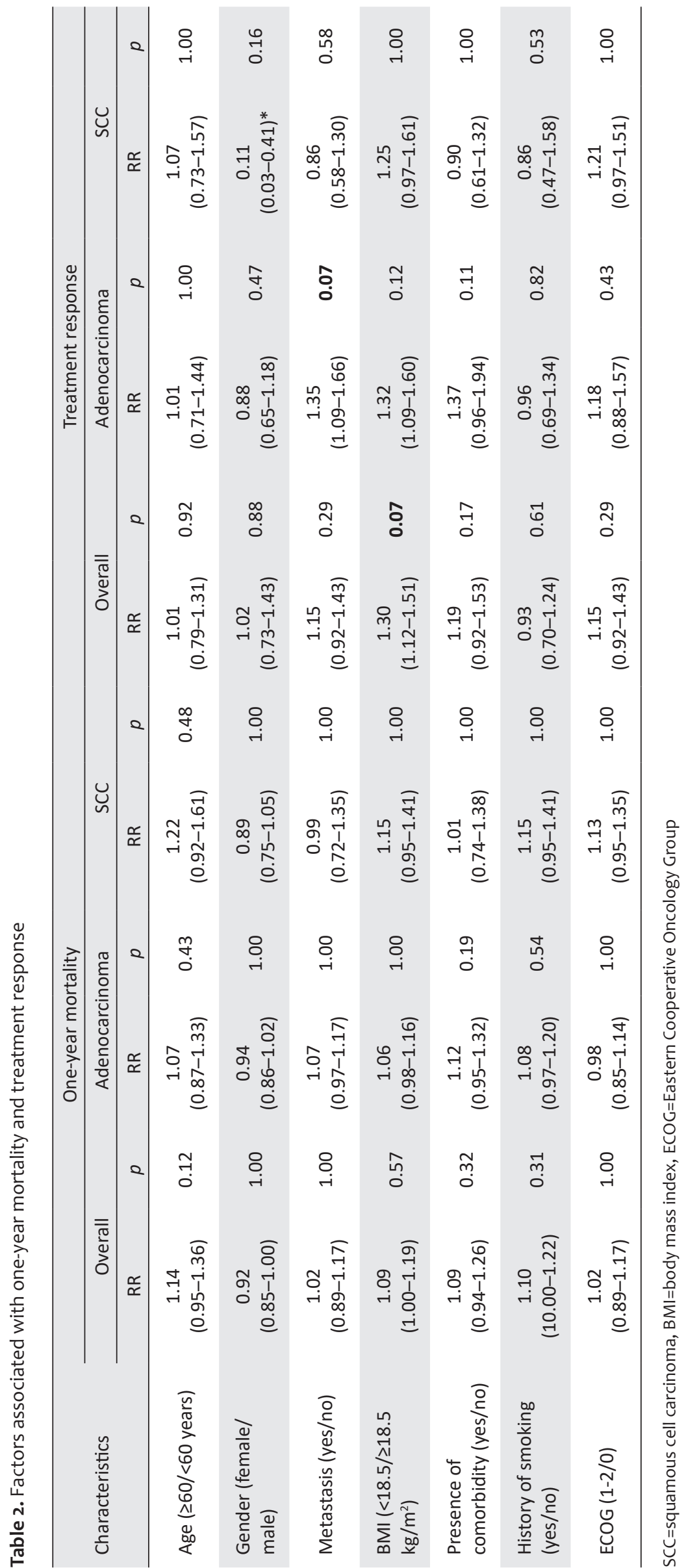


progression. ${ }^{26}$ Second, the period of observation in this study was one-year. As adenocarcinoma patients had a higher risk of progressive disease than squamous cell carcinoma patients, higher mortality could be shown in the adenocarcinoma group if the observation was performed for a longer period. ${ }^{27} \mathrm{~A}$ study conducted by Fesinmeyer et $\mathrm{a}^{28}$ showed a similar result. Squamous cell carcinoma patients had lower survival rates compared with adenocarcinoma patients (hazard ratio $=1.05$, 95\% $\mathrm{Cl}=1.03-1.06)$, despite squamous cell carcinoma being diagnosed at an earlier stage. However, this result contrasted with the findings of Ichinose et $\mathrm{al}^{12}$ that histological subtype was not a significant prognostic factor. The discrepancy could be due to different subject populations. Their study involved patients with an early stage of NSCLC, whereas ours only included patients with the advanced stage.

Being underweight was an important prognostic factor in this study. Underweight patients had higher mortality risk and a higher risk of progressive disease than the non-underweight group. A systematic review and meta-analysis confirmed this finding as each $5 \mathrm{~kg} /$ $\mathrm{m}^{2}$ increase in BMI indicated a $14 \%$ lower risk of total mortality. ${ }^{29} \mathrm{~A}$ cohort retrospective study also showed that higher BMI was associated with lower risk of progressive disease. ${ }^{30}$ These findings suggested that being underweight was a risk factor for lung cancer mortality and disease progression. The explanation was that underweight and cachexia were strongly associated with higher inflammation, higher catabolism, and a higher risk of progression, which could be worsened by chemotherapy. ${ }^{31}$ However, this finding did not imply that gaining weight during the treatment could improve survival and slow down the disease progression.

Smoking was not a significant determinant of mortality in this study. This result was contrary to the findings of Tammemagi et $\mathrm{al}^{32}$ that smoking was a significant risk factor for mortality in all types of NSCLC patients. Compared with our study, the population of the previous study was not uniform and involved all stages of NSCLC. Thus, smoking possibly posed a higher risk of mortality in the overall stages of NSCLC but not in advanced stages of NSCLC. In this study, current smoker and ex-smoker were included as positive smoking status. The amount of cigarettes consumed and period of smoking were not recorded. It could be a confounding factor in this study. Further research is needed to confirm smoking as a direct risk factor for mortality in lung cancer.
Particularly in the squamous cell carcinoma group, we found that women had a higher risk of progressive disease compared to men. Conversely, a meta-analysis performed by Pinto et $\mathrm{al}^{33}$ showed that women had a favorable outcome $(\mathrm{HR}=0.73,95 \% \mathrm{Cl}=0.67-0.79$, $p<0.001)$. However, the study by Pinto et $\mathrm{al}^{33}$ included NSCLC patients with positive epidermal growth factor receptor who could have benefited from targeted therapy and were not sub-analyzed based on the histopathology type of NSCLC. Our study excluded patients receiving targeted therapy. According to another study by Sekine et al ${ }^{34}$ on all NSCLC patients receiving chemotherapy and targeted therapy, disease progression was noted in 36 of the 44 (82\%) female patients and 131 of the 160 (82\%) male patients. The median progression-free survival did not differ significantly between the sexes; 9.2 months for the women and 9.7 months for the men $(p=0.67)$. These different findings warrant further study on gender and tumor biology.

This study involves several limitations. First, some potential confounders could not be analyzed due to the nature of the retrospective study. We did not consider the type and dosage of chemotherapy drugs, length of treatment, and time from diagnosis to treatment, which may affect survival and disease progression. Second, our sample size was relatively small due to incomplete medical records of the subjects. Third, we did not perform multivariate analysis due to a limited number of study subjects. Minimum sample size was not achieved to obtain accurate data on mortality rates in both histology types of NSCLC because the study was conducted in only one center and a cancer registry has not been established. However, considering that few centers in Indonesia are treating advanced stages of NSCLC, we can generalize our study findings among the Indonesian population. In conclusion, squamous cell carcinoma type had comparable one-year mortality and disease progression rate with adenocarcinoma type in advanced stages of NSCLC. However, underweight patients had a higher risk of mortality and progressive disease.

\section{Conflict of Interest}

The authors affirm no conflict of interest in this study.

\section{Acknowledgment}

We are grateful to the Director, Head of Research, and Head of Medical Records at Dharmais Cancer Hospital for providing permission to conduct this study. We also thank Boxplot for editing this manuscript and Enago (www.enago.com) for the English language review. 
Funding Sources None.

\section{REFERENCES}

1. Rafiemanesh H, Mehtarpour M, Khani F, Hesami SM, Shamlou R, Towhidi $\mathrm{F}$, et al. Epidemiology, incidence and mortality of lung cancer and their relationship with the development index in the world. J Thorac Dis. 2016;8(6):1094-102.

2. Bray F, Ferlay J, Soerjomataram I, Siegel RL, Torre LA, Jemal A. Global cancer statistics 2018: GLOBOCAN estimates of incidence and mortality worldwide for 36 cancers in 185 countries. CA Cancer J Clin. 2018;68(6):394-424.

3. Cheng TY, Cramb SM, Baade PD, Youlden DR, Nwogu C, Reid $M E$. The international epidemiology of lung cancer: latest trends, disparities, and tumor characteristics. J Thorac Oncol. 2016;11(10):1653-71.

4. Postmus PE, Kerr KM, Oudkerk M, Senan S, Waller DA, Vansteenkiste J, et al. Early and locally advanced non-smallcell lung cancer (NSCLC): ESMO clinical practice guidelines for diagnosis, treatment and follow-up. Ann Oncol. 2017 Jul;28(suppl_4):iv1-21.

5. Hu XL, Xu ST, Wang XC, Hou DN, Chen CC, Song YL, et al. Prevalence of and risk factors for presenting initial respiratory symptoms in patients undergoing surgery for lung cancer. $J$ Cancer. 2018;9(19):3515-21.

6. Ettinger DS, Wood DE, Aisner DL, Akerley W, Bauman J, Chirieac LR, et al. Non-small cell lung cancer, version 5.2017, NCCN clinical practice guidelines in oncology. J Natl Compr Canc Netw. 2017;15(4):504-35.

7. Harrison LD, Zhang-Salomons J, Mates M, Booth CM, King WD, Mackillop WJ. Comparing effectiveness with efficacy: outcomes of palliative chemotherapy for non-small-cell lung cancer in routine practice. Curr Oncol. 2015;22(3):184-91.

8. Xia W, Yu X, Mao Q, Xia W, Wang A, Dong G, et al. Improvement of survival for non-small cell lung cancer over time. Onco Targets Ther. 2017;10:4295-303.

9. Rinaldi S, Berardi R. Lung cancer prognosis: can histological patterns and morphological features have a role in the management of lung cancer patients? Ann Transl Med [Internet]. 2017;5(17):353.

10. Berardi R, Rinaldi S, Santoni $M$, Newsom-Davis T, Tiberi $M$, Morgese $F$, et al. Prognostic models to predict survival in patients with advanced non-small cell lung cancer treated with first-line chemo- or targeted therapy. Oncotarget. 2016;7(18):26916-24.

11. Mäkitaro R, Pääkko P, Huhti E, Bloigu R, Kinnula VL. Prospective population-based study on the survival of patients with lung cancer. Eur Respir J. 2002;19(6):1087-92.

12. Ichinose $\mathrm{Y}$, Hara N, Ohta M, Yano T, Maeda K, Asoh H, et al. Is $T$ factor of the TNM staging system a predominant prognostic factor in pathologic stage I non-small-cell lung cancer? A multivariate prognostic factor analysis of 151 patients. J Thorac Cardiovasc Surg. 1993;106(1):90-4.

13. Ferguson MK, Wang J, Hoffman PC, Haraf DJ, Olak J, Masters $G A$, et al. Sex-associated differences in survival of patients undergoing resection for lung cancer. Ann Thorac Surg. 2000;69(1):245-50.

14. Mahesh PA, Archana S, Jayaraj BS, Patil S, Chaya SK, Shashidhar $\mathrm{HP}$, et al. Factors affecting 30-month survival in lung cancer patients. Indian J Med Res. 2012;136(4):614-21.

15. Olaussen KA, Postel-Vinay S. Predictors of chemotherapy efficacy in non-small-cell lung cancer: a challenging landscape. Ann Oncol. 2016;27(11):2004-16.

16. Edge SB, Compton CC. The American Joint Committee on Cancer: the 7 th edition of the AJCC cancer staging manual and the future of TNM. Ann Surg Oncol. 2010;17(6):1471-4.
17. Travis WD, Brambilla E, Nicholson AG, Yatabe Y, Austin JHM, Beasley MB, et al. The 2015 World Health Organization classification of lung tumors: impact of genetic, clinical and radiologic advances since the 2004 classification. J Thorac Oncol. 2015;10(9):1243-60.

18. Schwartz LH, Litière S, de Vries E, Ford R, Gwyther S, Mandrekar $S$, et al. RECIST 1.1-update and clarification: from the RECIST committee. Eur J Cancer. 2016;62:132-7.

19. Harsal A, Suratman E, Tambunan T. Overview of lung cancer in Dharmais National Cancer Hospital, Jakarta, Indonesia. J Thorac Oncol. 2007;2(8):S564.

20. Wu YL, Zhou Q. Lung cancer management in the Asia-Pacific region: what's the difference compared with the United States and Europe? Results of the second Asia Pacific Lung Cancer Conference. J Thorac Oncol. 2007;2(6):574-6.

21. Thomas A, Chen Y, Yu T, Jakopovic M, Giaccone G. Trends and characteristics of young non-small cell lung cancer patients in the United States. Front Oncol. 2015;5:113.

22. Kawase A, Yoshida J, Ishii G, Nakao M, Aokage K, Hishida $\mathrm{T}$, et al. Differences between squamous cell carcinoma and adenocarcinoma of the lung: are adenocarcinoma and squamous cell carcinoma prognostically equal? Jap J Clin Oncol. 2012;42(3):189-95.

23. Simmons CP, Koinis F, Fallon MT, Fearon KC, Bowden J, Solheim TS, et al. Prognosis in advanced lung cancer--A prospective study examining key clinicopathological factors. Lung Cancer. 2015;88(3):304-9.

24. Jang RW, Caraiscos VB, Swami N, Banerjee S, Mak E, Kaya E, et al. Simple prognostic model for patients with advanced cancer based on performance status. J Oncol Pract. 2014;10(5):e335-41.

25. Kawaguchi T, Takada M, Kubo A, Matsumura A, Fukai S, Tamura $A$, et al. Performance status and smoking status are independent favorable prognostic factors for survival in non-small cell lung cancer: a comprehensive analysis of 26,957 patients with NSCLC. J Thorac Oncol. 2010;5(5):620-30.

26. Yuan P, Cao JL, Rustam A, Zhang C, Yuan XS, Bao FC, et al. Time-to-progression of NSCLC from early to advanced stages: an analysis of data from SEER registry and a single institute. Sci Rep. 2016;6:28477.

27. Richardson DB, Keil AP, Cole SR, MacLehose RF. Observed and expected mortality in cohort studies. Am J Epidemiol. 2017;185(6):479-86.

28. Fesinmeyer MD, Goulart B, Blough DK, Buchwald D, Ramsey SD. Lung cancer histology, stage, treatment, and survival in American Indians and Alaska Natives and whites. Cancer. 2010;116(20):4810-6.

29. Wang J, Xu H, Zhou S, Wang D, Zhu L, Hou J, et al. Body mass index and mortality in lung cancer patients: a systematic review and meta-analysis. Eur J Clin Nutr. 2018;72(1):4-17.

30. Zhong J, Zheng Q, Gao E, Dong Z, Zhao J, An T, et al. Influence of body mass index on the therapeutic efficacy of gemcitabine plus cisplatin and overall survival in lung squamous cell carcinoma. Thorac cancer. 2018;9(2):291-7.

31. Aoyagi T, Terracina KP, Raza A, Matsubara H, Takabe K. Cancer cachexia, mechanism and treatment. World J Gastrointest Oncol. 2015;7(4):17-29.

32. Tammemagi CM, Neslund-Dudas C, Simoff M, Kvale P. Smoking and lung cancer survival: the role of comorbidity and treatment. Chest. 2004;125(1):27-37.

33. Pinto JA, Vallejos CS, Raez LE, Mas LA, Ruiz R, Torres-Roman $J S$, et al. Gender and outcomes in non-small cell lung cancer: an old prognostic variable comes back for targeted therapy and immunotherapy? ESMO Open. 2018;3(3):e000344.

34. Sekine I, Sumi $M$, Ito $Y$, Tanai $C$, Nokihara $H$, Yamamoto $N$, et al. Gender difference in treatment outcomes in patients with stage III non-small cell lung cancer receiving concurrent chemoradiotherapy. Japanese J Clin Oncol. 2009;39(11):707-12. 